\title{
Time-out avoidance from a behavior-independent contingency
}

JOHN R. THOMAS

INSTITUTE FOR BEHAVIORAL RESEARCH, SILVER SPRING, MARYLAND

\begin{abstract}
Pigeons were maintained on a TO avoidance baseline with no specific pattern of responding required in the presence of the stimulus associated with positive reinforcement. Rate of TO avoidance was found to be inversely related to the RS interval. When average reinforcement frequency was increased for one bird, there was a decrease in TO avoidance rate.
\end{abstract}

Problem

A time-out (TO) may function as a negative reinforcer when it involves the removal of the opportunity to obtain positive reinforcement. Studies concerned with the investigation of behaviors maintained by the avoidance of primary negative reinforcers, such as electric shock, have always employed only a single response, unless the study was explicitly concerned with other concurrent behaviors. Studies concerned with behaviors maintained by TO avoidance have almost always employed a concurrent specified pattern of responding on the positive reinforcement schedule (e.g., Ferster, 1958; Morse \& Herrnstein, 1956; Thomas, 1964; Zimmerman, 1963)。

Baer $(1960,1962)$ has maintained behavior that avoided reinforcement withdrawal which involved the interruption of a reinforcing stimulus situation rather than of a concurrent behavioral schedule. Baer's procedure appears to be operationally more comparable to those avoidance procedures in which behaviors are maintained by electric shock avoidance. The present experiment studied TO avoidance with a procedure in which the concurrent baseline of positive reinforcement was a behavior-independent contingency (Findley, 1962) which required no specified behavior.

\section{Method}

The Ss were two adult male White Carneaux pigeons (T3 and T6) maintained at about $80 \%$ of their free-feeding weight. The apparatus was a standard single key pigeon chamber with associated programming and recording equipment. The Ss were first trained on the behaviorindependent contingency. Food reinforcement was presented occasionally, independent of any behavior. A reinforcement consisted of a 4-sec. presentation of the food tray. The response key was illuminated with a green key light and in the presence of the green key light food was presented according to an uncorrelated VI 3 reinforcement schedule. Occasionally, the response key was illuminated with a red light for a 5-min. period. During the red key light, no reinforcements were presented. The procedure in the presence of the red key light established the TO condition.
Following the above procedure the Ss were exposed to the TO avoidance schedule. The avoidance schedule was such that each response on the key, while the green key light was on, postponed the occurrence of the 5-min. TO for a period of $30 \mathrm{sec} .(\mathrm{RS}=30 \mathrm{sec}$. $)$. Successive TOs occurred every $30 \mathrm{sec}$. when no response occurred on the response key ( $\mathrm{SS}=30 \mathrm{sec}$.). In order to control for any superstitious maintenance of responding on the key, a 4-sec. delay interval was always programmed between a response on the key and the possibility of the occurrence of a food reinforcement. The first session during which the avoidance schedule was programmed began with the red key light on (TO stimulus). The red key light remained on until the $\mathrm{S}$ responded on the key and escaped from it, thereby producing the green key light associated with the uncorrelated VI schedule. After the establishment of behavior on the response key, the escape contingency was removed from the program and the TO duration was set at $5 \mathrm{~min}$. The SS interval was reduced from $30 \mathrm{sec}$. to $10 \mathrm{sec}$. and remained at the new value for the duration of this study. The RS interval was set at $60 \mathrm{sec}$. The Ss were run on these values for a number of sessions until stable behavioral performances were established. Following these sessions, 12 sessions were programmed without TO occurrence.

The RS interval was manipulated in order to investigate control by this variable of responding on the avoidance key. The RS intervals programmed for the Ss were: $20,30,60$, and $120 \mathrm{sec}$. The frequency of reinforcement on the behavior-independent contingency was manipulated for T3 by increasing the average frequency of food reinforcement from one per $3 \mathrm{~min}$. to one per min. (VI 3 to VI 1). With the uncorrelated VI 1 reinforcement schedule in effect, T3 was again exposed to the same four RS intervals.

\section{Results}

Responding on the key which terminated the TO and produced the stimulus for the uncorrelated VI schedule was readily established and maintained with both Ss. Behavior continued on the response key after the escape contingency was removed from the program. Avoidance responding occurred on the key at an overall rate of about 2-3 responses per minute. When the TOs were not programmed, responding on the key declined to zero during the first five sessions and remained at that value until the reinstatement of the avoidance program seven sessions later.

The mean response rates (responses per min.) for the two Ss for each of the RS intervals are presented 


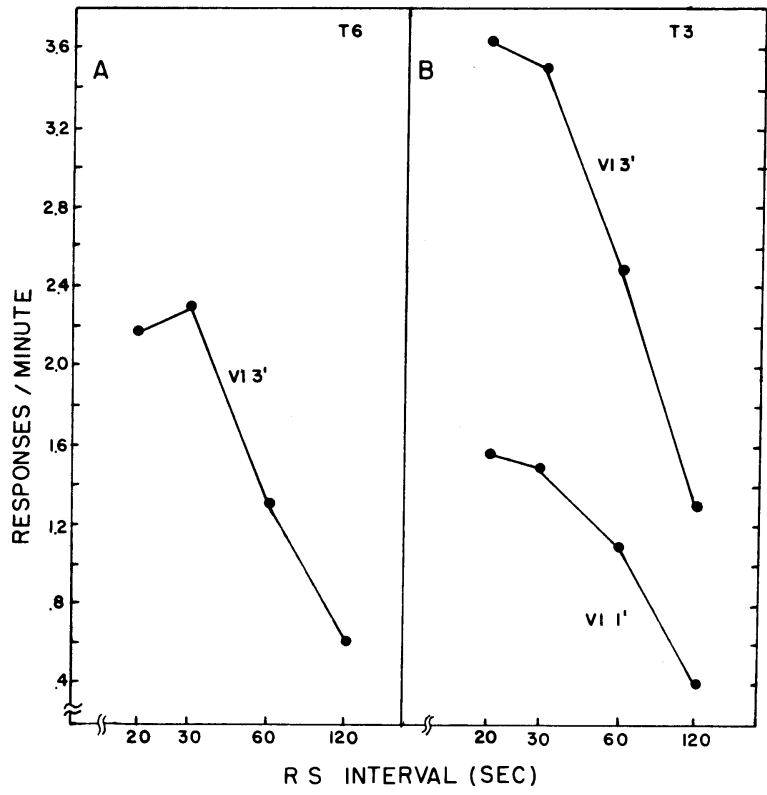

Fig. 1. Time-out avoidance response rates for both $\mathrm{Ss}$ as a function of RS interval.

in Fig. 1. It may be seen that, in general, response rate increases as the RS interval decreases. In Fig. 1B are shown the response rates for $\mathrm{T} 3$ at each $\mathrm{RS}$ interval for both the uncorrelated VI 3 and the uncorrelated VI 1 schedules. It may be seen that the same general functional relationship between response rate and RS interval is obtained with both VI's, with lower absolute rates for the schedule associated with the higher reinforcement frequency.

\section{Diseussion}

The present study demonstrated that behavior which serves to postpone a TO can be maintained when there is no specific pattern of responding required in the presence of the stimulus associated with positive reinforcement. The rate of responding in the present study was inversely related to the interval by which each response postponed the TO (RS interval). The inverse relationship between response rate and $\mathrm{RS}$ interval is similar to the relation that has been found for electric shock avoidance baselines (Sidman, 1953). The inverse relationship has been reported previously with nondiscriminated TO avoidance baselines (Ferster, 1958; Morse \& Herrnstein, 1956; Zimmerman, 1963). The similar relationship between response rate and $\mathrm{RS}$ interval suggests that the same type of aversive temporal controls are operating in both cases. A single response in the present study both postponed the occurrence of a TO and also postponed the possibility of food reinforcement for at least $4 \mathrm{sec}$. (the delay interval). In this sense, a response is both reinforced and punished. The combination of those effects may contribute to the production of overall low response rates.

The lower avoidance response rates which occurred for $\mathrm{T} 3$ when the reinforcement frequency was increased from an average of one per $3 \mathrm{~min}$. to one per min. suggests that there is a higher sensitivity of more intermittently reinforced behavior to the effects of TO than less intermittently reinforced behavior. A decrease in TO avoidance behavior when reinforcement frequency was increased has been reported previously when a specific pattern of responding was concurrently required on the positive reinforcement schedule (Thomas, 1964). The present study suggests that the increased ability of less frequently reinforced behavior to maintain TO avoidance is independent of any specific pattern of responding on the positively reinforced schedule. The sensitivity of more intermittently reinforced behavior to the effects of TO has also been demonstrated with the matching to sample procedure (Ferster \& Appel, 1961)。

\section{References}

Baer, D. M. Escape and avoidance response of preschool children to two schedules of reinforcement withdrawal. J. exp. Anal. Behav., 1960, 3, 155-158.

Baer, D. M. A technique of social reinforcement for the study of child behavior: behavior avoiding reinforcement withdrawal. Child Develpm., 1962, 33, 847-858.

Ferster, C. B. Control of behavior in chimpanzees and pigeons by time-out from positive reinforcement. Psychol. Monogr., 1958, 72, No. 8 (Whole No. 461).

Ferster, C. B., \& Appel, J. B. Punishment of S-delta responding in matching to sample by time-out from positive reinforcement. $J$. exp. Anal. Behav., 1961, 4, 45-56.

Findley, J. D. An experimental outline for building and exploring multi-operant behavior repertoires. J. exp. Anal. Behav., 1962, $5,113-166$.

Morse, W. H., \& Herrnstein, R. J. The maintenance of avoidance behavior using the removal of a conditioned positive reinforcer as the aversive stimulus, Amer. Psychologist, 1956, 11, 430 .

Sidman, M. Two temporal parameters of the maintenance of avoidance behavior by the white rat. J. comp. physiol. Psychol., 1953, $46,253-261$.

Thomas, J. R. Avoidance of time-out from two VI schedules of positive reinforcement. J. exp. Anal. Behav., 1964, 7, 168.

Zimmerman, J. A multiple schedule of time-out avoidance with monkeys. Amer. Psychologist, 1963, 18, 422.

\section{Note}

1. The research was conducted at the Laboratory of Psychopharmacology, Maryland University, and was supported by Public Health Service Research Grant MH-01604 from the National Institute of Mental Health. Portions of this research are based upon Experiment VI of a thesis submitted to Maryland University in partial fulfillment of the requirements of the Ph.D. degree. 